\title{
Metabolic Syndrome as independent risk factor of poor glycemic control in type 2 diabetic patients
}

\section{Richard Buendia ${ }^{1-2}$,Catalina Tobón ${ }^{1}$, Oscar Paz ${ }^{1}$, Eleonora Vizcaíno ${ }^{1}$, Amanda Páez ${ }^{1}$, Adelaida Espinosa ${ }^{1}$ Sonia Velandia ${ }^{2}$, Margarita Sánchez $^{2}$, María Helena Zappa ${ }^{2}$,Alejandra Contreras ${ }^{2}$, Alejandra Morales ${ }^{2}$.}

1. Hospital Central de la Policia Nacional. Bogotá-Colombia 2. Colsubsidio. Centro médico de especialistas. Bogotá -Colombia

Type 2 diabetes mellitus is considered a disease of epidemic proportions. Sustained glycemic control and the control of its associated factors are important to prevent macro and microvascular complications.

\section{OBJECTIVE}

This study aims to determine the factors associated with poor glycemic control, defined as $\mathrm{HbA1c}$ greater than $7 \%$, in type 2 diabetic patients, belonging to the cardiovascular risk program of the National Police Hospital in Colombia.

\section{METHODS}

This is a descriptive cross-sectional study. Univariate and multivariate analysis were performed on the factors associated with poor glycemic control in type 2 diabetes patients.

\section{RESULTS}

A sample of 3417 patients belonging to the cardiovascular risk program was selected, and 1058 patients with type 2 diabetes mellitus were included. Independent factors of poor glycemic control were found, including: an LDL cholesterol $>100 \mathrm{mgdl} \mathrm{OR}=1.47(95 \% \mathrm{Cl} 1.12$ to $1.944, \mathrm{p}=0.006) ; \mathrm{HDL}<40 \mathrm{mg} / \mathrm{dl}$ in men and $<50 \mathrm{mg} / \mathrm{dl}$ in women $\mathrm{OR}=1.44(95 \% \mathrm{Cl} 1.043$ to $1.99, \mathrm{p}=0.027)$; Duration of diabetes $\mathrm{OR}=1.066(95 \% \mathrm{Cl} 1.049$ to $1.084, \mathrm{p}=0.001)$; Microalbuminuria $>30 \mathrm{mg} / \mathrm{g}$ creatinuria $\mathrm{OR}=1.484(95 \% \mathrm{Cl} 1.11$ to $1.978, \mathrm{p}=0.007)$ and IDF criteria of metabolic syndrome $\mathrm{OR}=2.30(95 \% \mathrm{Cl} 1.47$ to $3.59, \mathrm{p}=0.001)$; adjusting for age, smoking, body mass index and triglycerides.
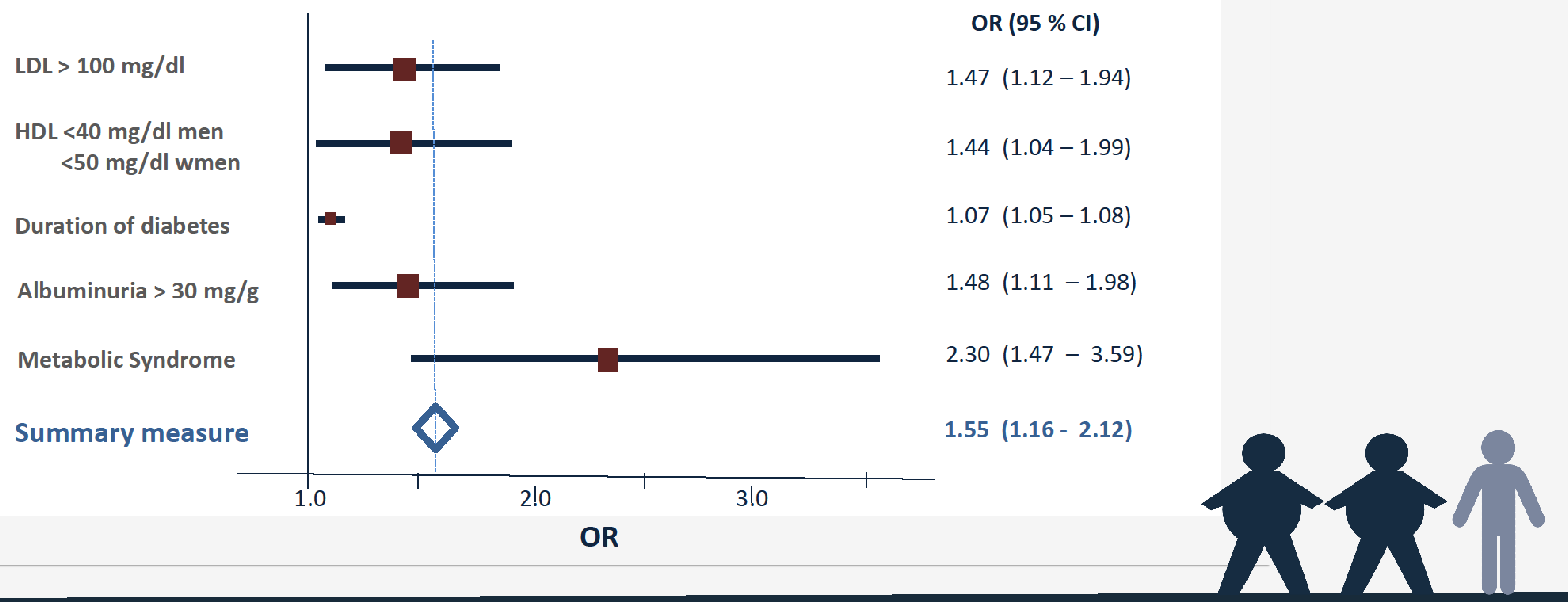

\section{CONCLUSION}

The Metabolic syndrome is an independent factor associated with poor glycemic control in type 2 diabetes mellitus. Intensification of therapeutic lifestyle changes has been applied to diabetic patients belonging to the Cardiovascular Risk Program, in order to control the associated risk factors and reduce the presence of Metabolic Syndrome.

\section{References}

1. Vouri SM, Shaw RF, Waterbury NV, Egge JA, Alexander B. Prevalence of achievement of $A 1 c$, blood pressure, and cholesterol $(A B C)$ goal in veterans with diabetes. Journal of managed care pharmacy : JMCP. 2011;17(4):30412.

2. Hajat $C$, Shather Z. Prevalence of metabolic syndrome and prediction of diabetes using IDF versus ATPIII criteria in a Middle East population. Diabetes research and clinical practice. 2012;98(3):481-6.

3. Guzman JR, et al. Treatment of type 2 diabetes in Latin America: a consensus statement by the medical associations of 17 Latin American countries. Latin American Diabetes Association. Revista panamericana de salud publica $=$ Pan American journal of public health. 2010;28(6):463-71. 